\title{
On the Application of Electron Energy-Loss Spectroscopy for Investigating Nanostructure of Soot from Different Fuels
}

\author{
Carmela Russo ${ }^{1}$, Miroslawa Pawlyta ${ }^{2}$, Anna Ewa Tomiczek ${ }^{2} \mathbb{D}$, Anna Ciajolo ${ }^{1}$ and Barbara Apicella ${ }^{1, *(D)}$ \\ 1 Istituto di Scienze e Tecnologie per l'Energia e la Mobilità Sostenibili, STEMS-CNR, P.le Tecchio 80, \\ 80135 Naples, Italy; carmela.russo@stems.cnr.it (C.R.); anna.ciajolo@cnr.it (A.C.) \\ 2 Faculty of Mechanical Engineering, Silesian University of Technology, 44-105 Gliwice, Poland; \\ miroslawa.pawlyta@polsl.pl (M.P.); anna.tomiczek@polsl.pl (A.E.T.) \\ * Correspondence: barbara.apicella@stems.cnr.it
}

Citation: Russo, C.; Pawlyta, M.; Tomiczek, A.E.; Ciajolo, A.; Apicella, B. On the Application of Electron Energy-Loss Spectroscopy for Investigating Nanostructure of Soot from Different Fuels. Fuels 2021, 2, 367-375. https://doi.org/10.3390/ fuels2030021

Academic Editor: Martin Olazar

Received: 11 July 2021

Accepted: 10 September 2021

Published: 16 September 2021

Publisher's Note: MDPI stays neutral with regard to jurisdictional claims in published maps and institutional affiliations.

Copyright: (c) 2021 by the authors. Licensee MDPI, Basel, Switzerland. This article is an open access article distributed under the terms and conditions of the Creative Commons Attribution (CC BY) license (https:// creativecommons.org/licenses/by/ $4.0 /)$.

\begin{abstract}
Soot is characterized by a multiscale structural organization; the only diagnostic tool that can give access to it is the transmission electron microscope (TEM). However, as it is a diffractionbased technique, TEM images only conjugate aromatic systems and, thus, it is particularly useful to combine it with electron energy-loss spectroscopy (EELS), which is able to provide quantitative information about the relative abundance of $\mathrm{sp}^{3}$ and $\mathrm{sp}^{2}$ hybridized carbon. In this paper, a method for the EELS spectrum analysis of carbonaceous materials, recently developed for electron-irradiated graphite and glassy carbon composition analysis, has been applied for the first time on soot samples, in order to test its performance in soot nanostructure study in combination with TEM and highresolution TEM (HRTEM). Soot samples analyzed were collected in the soot inception region of premixed flames of different hydrocarbon fuels. EELS, in agreement with TEM and HRTEM, showed a quite disordered and heterogeneous structure for young soot, with a relatively low $\mathrm{sp}^{2}$ content and slight presence of fullerene-like structures, more evident in the case of methane soot hinting to the effect of more saturated aliphatic fuels on soot characteristics at soot inception.
\end{abstract}

Keywords: soot; TEM; HRTEM; EELS; soot nanostructure; premixed flames

\section{Introduction}

Soot research is important given the effect of soot emission on climate change and environmental issues. However, its characterization is a very difficult task due to complex structure and nanometric size of the soot particles. In particular, soot is characterized by a multiscale organization and cannot be considered neither wholly crystalline, nor amorphous. Soot is composed of three-dimensional aggregates, consisting of complexly branched chains of spherical primary particles, which in turn are composed of concentrically arranged carbon layers. These layers are parallel to each other with interplanar distances higher with respect to that of graphite (about $0.335 \mathrm{~nm}$ ), featuring a structure at the atomic scale corresponding to a turbostratic, i.e., biperiodic, stacking of a few nanometer-sized layers [1].

Due to this characteristic multi-scale organization, soot can be clearly distinguished from other carbon solid particles when observed by transmission electron microscopy (TEM). TEM, indeed, is the only diagnostic tool giving access to the soot multi-scale organization and especially nanostructure, which can be explored by the high resolution mode of TEM (HRTEM), measuring structural parameters through mathematical approaches for image analysis [1]. However, it should be emphasized that this technique has significant limitations, such as being labor-intensive, having limited statistics, and being limited by the loss of most of highly volatile species [2]. Moreover, being a diffraction-based technique, TEM images only aromatic systems whereas does not "see" $\mathrm{sp}^{3}$ bonding. While TEM imaging focuses on the inelastic interaction of the primary beam electrons with the electrons from the sample, inelastically scattering electrons can be measured by electron energy-loss 
spectroscopy (EELS). The analysis of the energy distribution of electrons that have come through the specimen reveals a wealth of chemical and electronic state information. For this reason, it is particularly useful to combine TEM with EELS [3].

Various carbonaceous materials, such as crystalline graphite, amorphous carbon, diamond-like carbon (DLC) films and fullerenes, as well as nanotubes, have been analyzed by EELS, making it possible to characterize differences in their structure and the relative abundance of $\mathrm{sp}^{3}$ and $\mathrm{sp}^{2}$ hybridized carbon [4]. This approach has already been proved to give interesting insight in soot composition and evolution during its formation and growth [5] and oxidation [6]. Indeed, EELS has been numbered among the spectroscopybased techniques that are more useful to trace soot maturation [7]. The spectrum of high energy losses shows values corresponding to the excitations of electrons from the localized orbitals of the sample to the unoccupied, delocalized orbitals with energy higher than the Fermi level. The K line of absorption edge for carbon is close to about $285 \mathrm{eV}$. It has a complex shape, in which several components can be distinguished:

- G1 peak at approximately $285 \mathrm{eV}$, corresponding to a $\mathrm{C}=\mathrm{C} \pi^{*}$ component;

- G2 peak at approximately $292 \mathrm{eV}$, corresponding to a $\mathrm{C}-\mathrm{C} \sigma^{*}$ component;

- G3 peak at approximately $300 \mathrm{eV}$, corresponding to a $\mathrm{C}=\mathrm{C} \sigma^{*}$ component.

In addition, two other components (G4 and G5 bands at approximately 287 and $289 \mathrm{eV}$, respectively) can be indicated, related to the presence of heteroatoms (oxygen or hydrogen) or the presence of carbon atoms connected by a $\mathrm{sp}^{2}$ bond, but not forming planar layers (e.g., fullerene-like structures) [8,9]. In particular, Nyberg et al. [10] found that C-K absorption spectra of C60 and C70 fullerenes consist of double-peaked $\pi^{*}$ component. Therefore, as reported also by other authors, shoulder on the high energy side of the $1 \mathrm{~s}$ to $\pi^{*}$ peak centered at $287 \mathrm{eV}$ (G4 bands) was attributed to non-planar sp ${ }^{2}$ bonds [11,12].

By analyzing the energy of inelastic scattered electrons (loss of electron energy after passing through the analyzed sample), one can obtain information on the chemical composition (electronic structure). For carbon, the core shell electrons can scatter only to the unoccupied antibonding $\sigma^{*}$ and $\pi^{*}$ states. The intensities of the transitions from $1 \mathrm{~s}$ to $\pi^{*}(\sim 285 \mathrm{eV})$ and $1 \mathrm{~s}$ to $\sigma^{*}(\sim 292 \mathrm{eV})$ are proportional to the density of states ( $\pi^{*}$ and $\sigma^{*}$ ) and can thus be used to calculate $\mathrm{sp}^{2}$ and $\mathrm{sp}^{3}$ content $[4,13]$ and to follow soot graphitization process [5].

In this paper, a method for the EELS spectrum analysis of carbonaceous materials recently developed for electron-irradiated graphite [8] and glassy carbon [14] composition analysis has been tested for the first time on soot samples. The article reports the results obtainable from a combined use of TEM, HRTEM, and EELS with this method on test soot samples, collected in premixed flames with different hydrocarbon fuels. The innovation of the method lies in the possibility to retrieve important information on the amount of planar $\mathrm{sp}^{2}$ and non-planar fullerene-like $\mathrm{sp}^{2}$ bonds, going beyond the identification of the $\mathrm{sp}^{2}$ hybridization degree.

\section{Materials and Methods}

Carbon particulate matter was thermophoretically sampled from laminar premixed flames. An ethylene flame and a methane flame (ethylene 3.0; methane 4.5 and oxygen 2.5, SOL S.p.A.) were produced on a McKenna burner (Holthuis \& Associates) at the same cold gas velocity $(4 \mathrm{~cm} / \mathrm{s})$ and different equivalent ratios $(\varphi), 3$ and 2.4, respectively, producing similar maximum flame temperatures ( $1670 \mathrm{~K}$ and $1650 \mathrm{~K}$, respectively). The mass flow rates were controlled by gas flow was controlled by Bronkhorst mass flow controllers (HI-TEC Type F201AC). Carbon particulate matter was collected at $8 \mathrm{~mm}$ of height above the burner in both the flames to collect young soot, i.e., soot just after soot inception region at its maximum formation rate $[5,15,16]$.

The samples were named in the paper ETI8 and MET8, referring to young soot from ethylene and methane flame, respectively.

Thermophoretic sampling was carried out by fast insertion of a glass plate $(75 \times 25$ $\times 1 \mathrm{~mm}$ ), inserted horizontally and rotating by a gear motor with a rotation speed of 1.4 
gear/s. The insertion/deposition time of the plate was regulated at $60 \mathrm{~ms}$ per lap to avoid the plate heating [16]. The insertions were repeated continuously many times reaching the total deposition time for each sample of $25 \mathrm{~s}$.

A scheme of the burner with the system for the thermophoretic sampling is reported in Figure 1. More experimental details are reported in a previous paper [16].

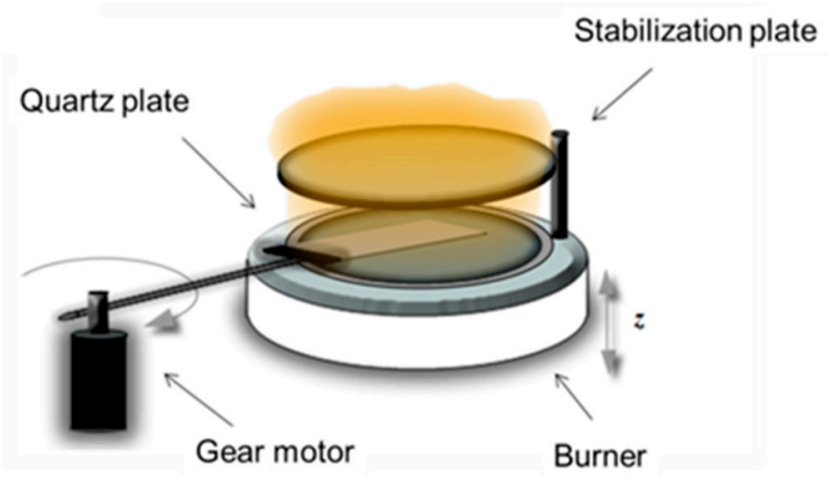

Figure 1. Scheme of the burner with the system for the thermophoretic sampling.

Carbon particulate samples were scratched from the glass plate and extracted with dichloromethane (DCM, $\mathrm{CH}_{2} \mathrm{Cl}_{2}$ ) (Sigma Aldrich, USA by Merck group, Darmstadt, Germany, purity $>99.9 \%$ ) for separating organic species (soluble in DCM) from solid carbon particles insoluble in DCM, referred to as soot.

Samples for TEM, HRTEM, and EELS studies were made by dispersing a small amount of soot in ethanol $\left(\mathrm{CH}_{3} \mathrm{OH}\right.$, Sigma Aldrich, USA by Merck group, Darmstadt, Germany, purity $>99.8 \%$ ). A drop of this dispersion was then applied to a microscopy copper grid covered with a lacey carbon layer. TEM studies were performed on S/TEM Titan 80-300 microscope from (FEI, Hillsboro, OR, USA), operating at $300 \mathrm{kV}$. The EELS spectra were acquired in the same microscope, operating at $80 \mathrm{kV}$ and equipped with a Gatan Tridiem 863 spectrometer (Gatan, Pleasanton, CA, USA). For EELS analysis, relatively large volumes of the material (approx. $50 \mathrm{~nm} \times 50 \mathrm{~nm}$ ) were subjected.

For such volumes, the carbon layers are anisotropically arranged (in all directions, there is no privileged orientation). An EELS energy resolution, measured as the full width at half maximum (FWHM) of the Zero Loss Peak (ZLP), was $1.8 \mathrm{eV}$. Energy loss spectra were recorded in two ranges: low energy losses $(<50 \mathrm{eV})$ and core loss $(270-360 \mathrm{eV})$. Six spectra were recorded for each sample. For spectral deconvolution, the FITYK program was used [17].

\section{Results and Discussion}

The TEM and HRTEM images of young ethylene and methane soot are reported in Figures 2 and 3, respectively. The images, reported at different magnifications, confirm the characteristic, multi-scale structure of the soot in the two tested samples, showing different aggregates made of smaller particles. Aggregates composed of single particles and containing thousands of such particles were observed (Figures 2a and 3a). It was a characteristic property of the tested samples, depending on the selected fragment of the observed sample, small or large aggregates were visible. 

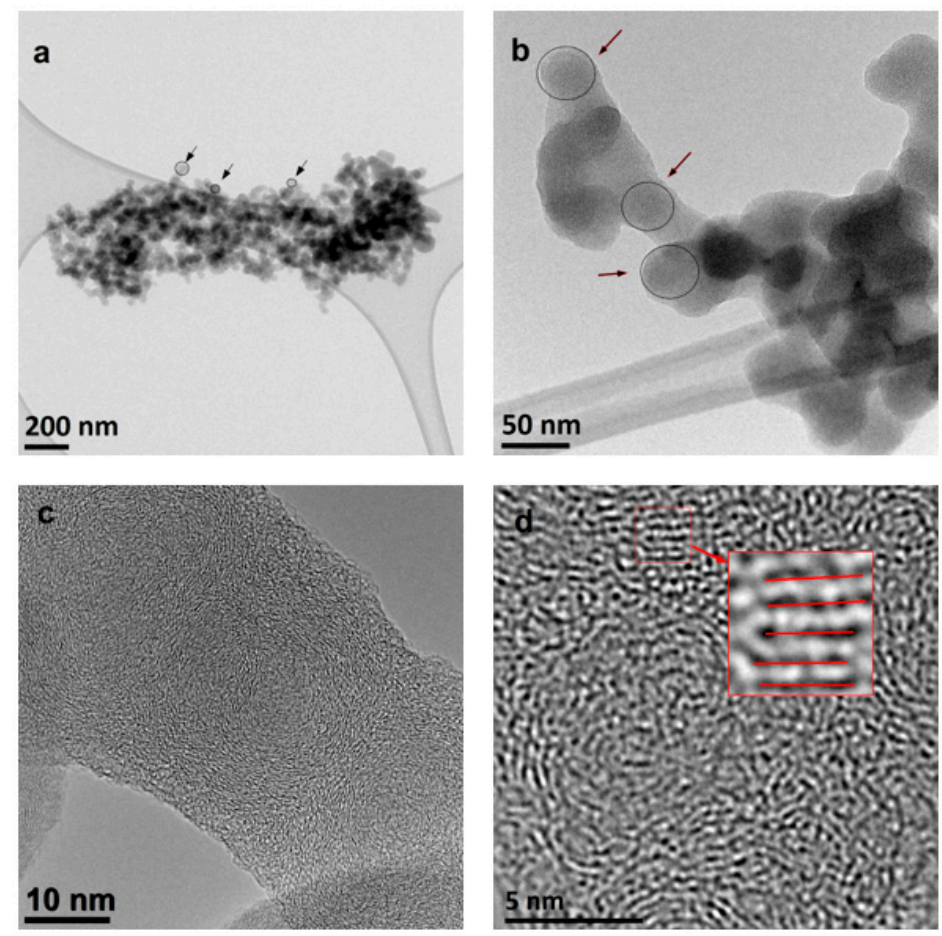

Figure 2. Multiscale organization of the young ethylene soot structure. TEM images obtained at different magnifications, as indicated by the reported scales (a-d) Black arrows in (b) indicate spherical soot particles. Red lines in (d) indicate the parallel arrangement of the defected carbon layers.
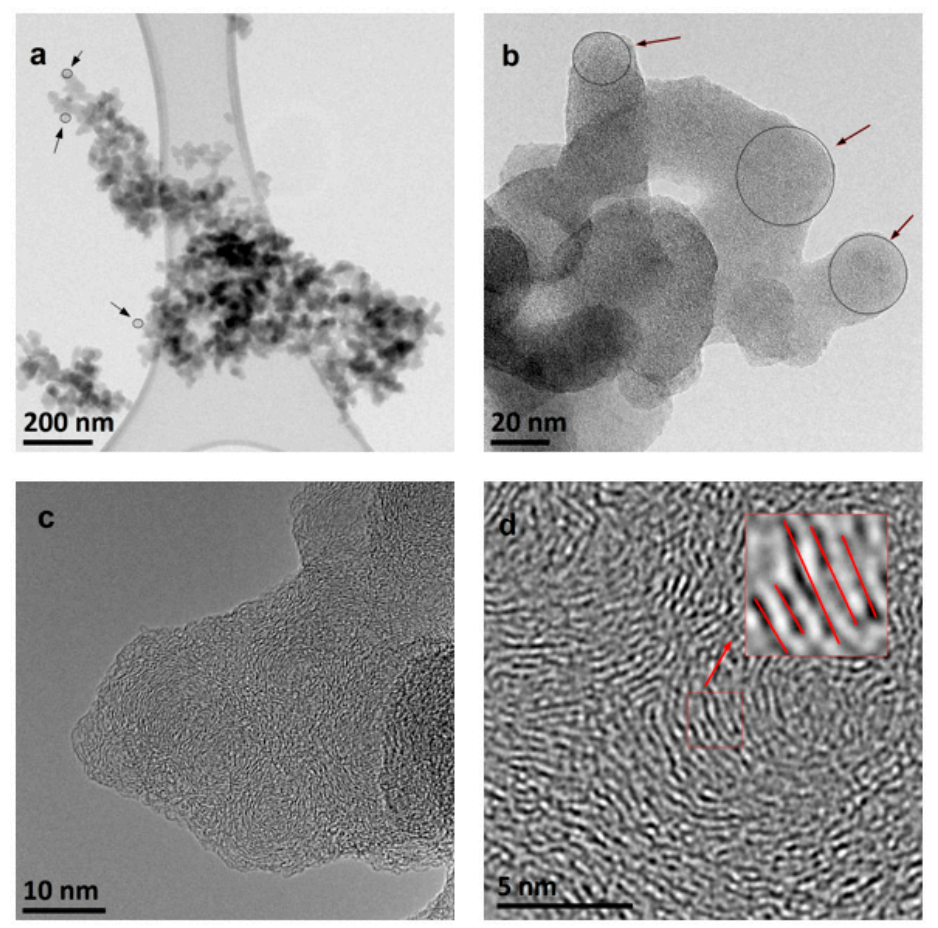

Figure 3. Multiscale organization of the young methane soot structure. TEM images obtained at different magnifications, as indicated by the reported scales (a-d) Black arrows in (b) indicate spherical soot particles. Red lines in (d) indicate the parallel arrangement of the defected carbon layers.

An average diameter of the individual particle size can be estimated to be around 30-50 nm (Figures $2 \mathrm{~b}$ and $3 \mathrm{~b}$ ). This broad estimate is due to the presence of large coalesced structures, with just few primary particles mainly located on the edge. Indeed, the individ- 
ual particles that make up the aggregates are not simple connected perfect spheres, with one embryo in the central part. Instead, numerous embryos, around which carbon layers have grown, can be noticed. These embryos fused at the early stage of soot formation and then the entire structure continued to grow. Therefore, in the pictures, the diameter of the primary particles forming the aggregates is not clearly identifiable (Figures $2 b$ and $3 b$ ).

As already observed in young soot in previous works [1,5], the presence of both graphitic-like and amorphous-like components in the young soot, visible in the HRTEM images (Figure 2c,d and Figure 3c,d), is remarkable. The arrangement of the carbon layers is also visible. Quantitative fringe analysis revealed that they are about $1-2 \mathrm{~nm}$ in size, arranged parallel to each other and approximately at a constant distance (about $0.35 \mathrm{~nm}$ ). Carbon layers are arranged concentrically around the embryos (and they are smaller in these areas), closer to the outer surface-parallel to this surface (and then longer). These inferences did not show any significant (noticeable) differences between young soot formed in methane and ethylene flames.

Figure 4 shows an exemplary spectrum (obtained for young ethylene soot) of electron energy losses in the low energy range $(<50 \mathrm{eV})$, which includes the ZLP band and the faintly visible band, corresponding to the $\pi \rightarrow \pi^{*}$ transitions $(6 \mathrm{eV})$ and the band corresponding to the collective oscillations of the valence electrons $(\pi+\sigma)$. The location of the plasmonic peak (energy approx. 22-26 eV) characterizes the electron density in the valence band and is an indicator of the degree of graphitization of the tested material [9]. The position of the peak was determined by taking the first derivative of the spectrum.

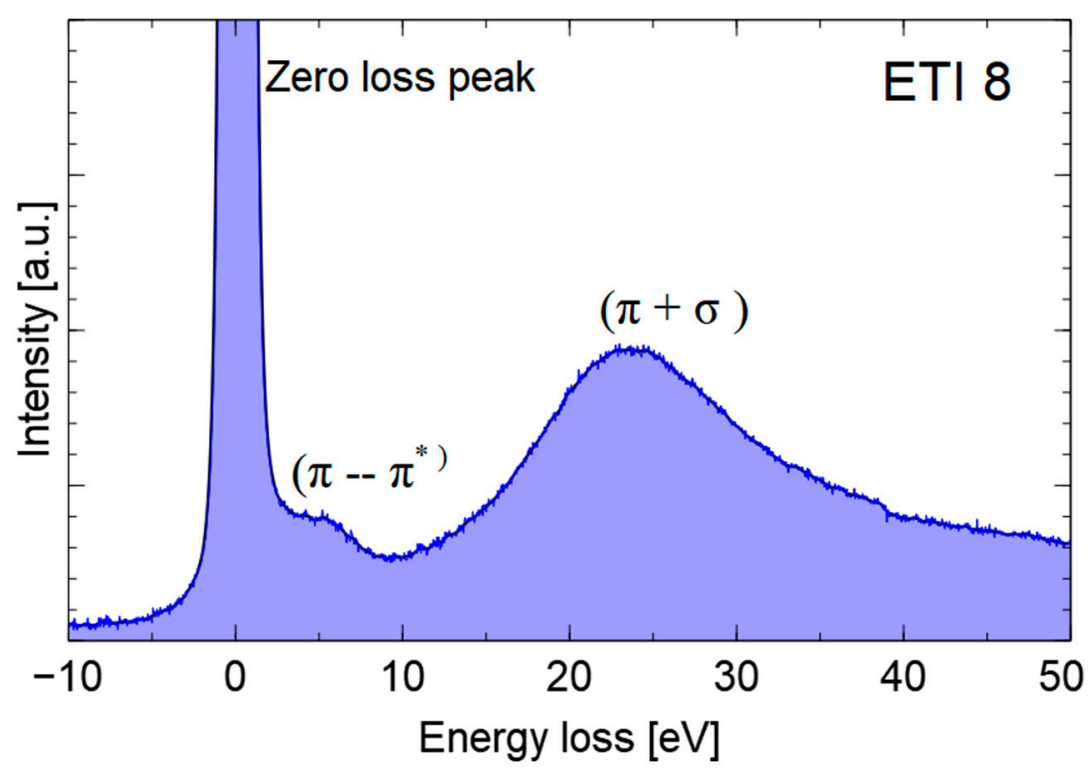

Figure 4. An example of the EELS spectrum of young ethylene soot. The range of low energy losses.

The position of this band is $27 \mathrm{eV}$ for highly oriented pyrolytic graphite (HOPG), which is higher than that observed for the two young soot samples and next to that assigned to amorphous carbon (approx. $23 \mathrm{eV}$ ), indicating a low level of graphitization of the samples.

An example of the $C_{K}$ absorption curve in the energy range, from 270 to $360 \mathrm{eV}$, is shown in Figure 5. It shows the peaks corresponding to the transitions from the $1 \mathrm{~s}$ orbital to $\pi^{*}$ (approx. $285 \mathrm{eV}$ ) and $\sigma^{*}$ (approx. $292 \mathrm{eV}$ ) and the band marked as MSR (Multiple Scattering Resonance, approx. $330 \mathrm{eV}$ ). A comparison of the $\mathrm{C}_{\mathrm{K}}$ absorption curves of the two soot samples is shown in Figure 6. The presented results are typical of low-graphitization carbon materials [18] and reveal that there are no significant differences between the investigated samples. 


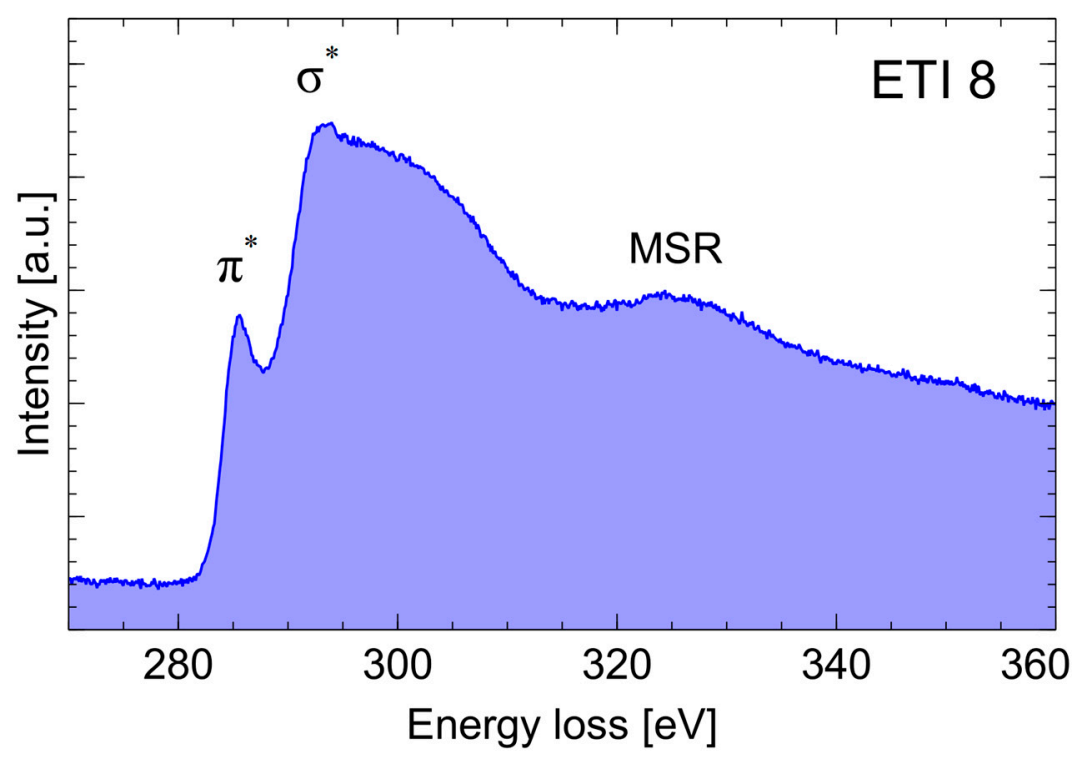

Figure 5. An example of the EELS spectrum of young ethylene soot. The absorption curve $\mathrm{C}_{\mathrm{K}}$.

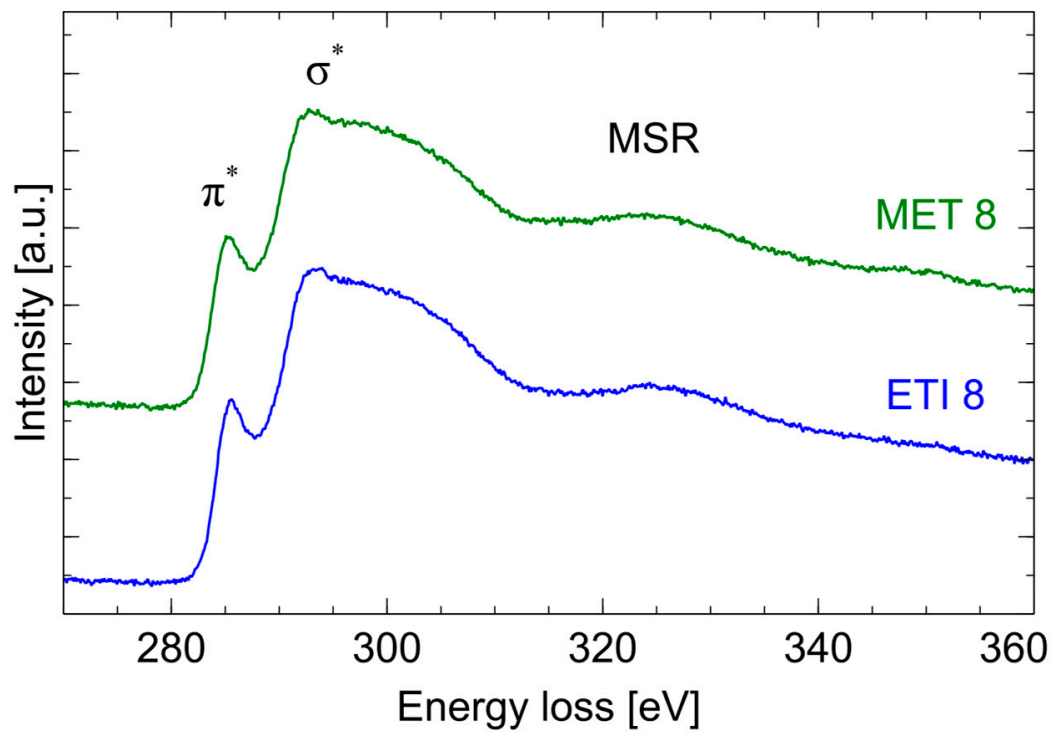

Figure 6. Comparison of the shape of the absorption curves $C_{K}$.

The percentage of $\mathrm{sp}^{2}$ hybridized carbon atoms was determined by analyzing the shape of the absorption curve $C_{K}$. For the obtained core-loss spectra background was subtracted and the multiple scattering was then removed by Fourier-ratio deconvolution with the low-loss spectrum obtained for exactly the same region of the sample. The maximum of the $\pi^{*}$ peak was fixed at $284.5 \mathrm{eV}$ to minimize systematic error from peak position. To determine the ratio of (planar) $\mathrm{sp}^{2}$ bonded carbon to total carbon, the spectra were fitted by five Gaussian peaks (Figure 7) [8]:

- the first Gaussian (G1) centered at $284.5 \mathrm{eV}$ ( $\mathrm{C}=\mathrm{C} \pi^{*}$ component);

- the second Gaussian (G2) centered at $291.75 \mathrm{eV}$ (C-C $\sigma^{*}$ component);

- the third Gaussian (G3) centered at $297.75 \mathrm{eV}$ (C=C $\sigma^{*}$ component);

- two additional (G4 and G5) 286-288 eV (due to the presence of additional heterospecies or the presence of a non-planar $\mathrm{sp}^{2}$-bonded carbon component). 

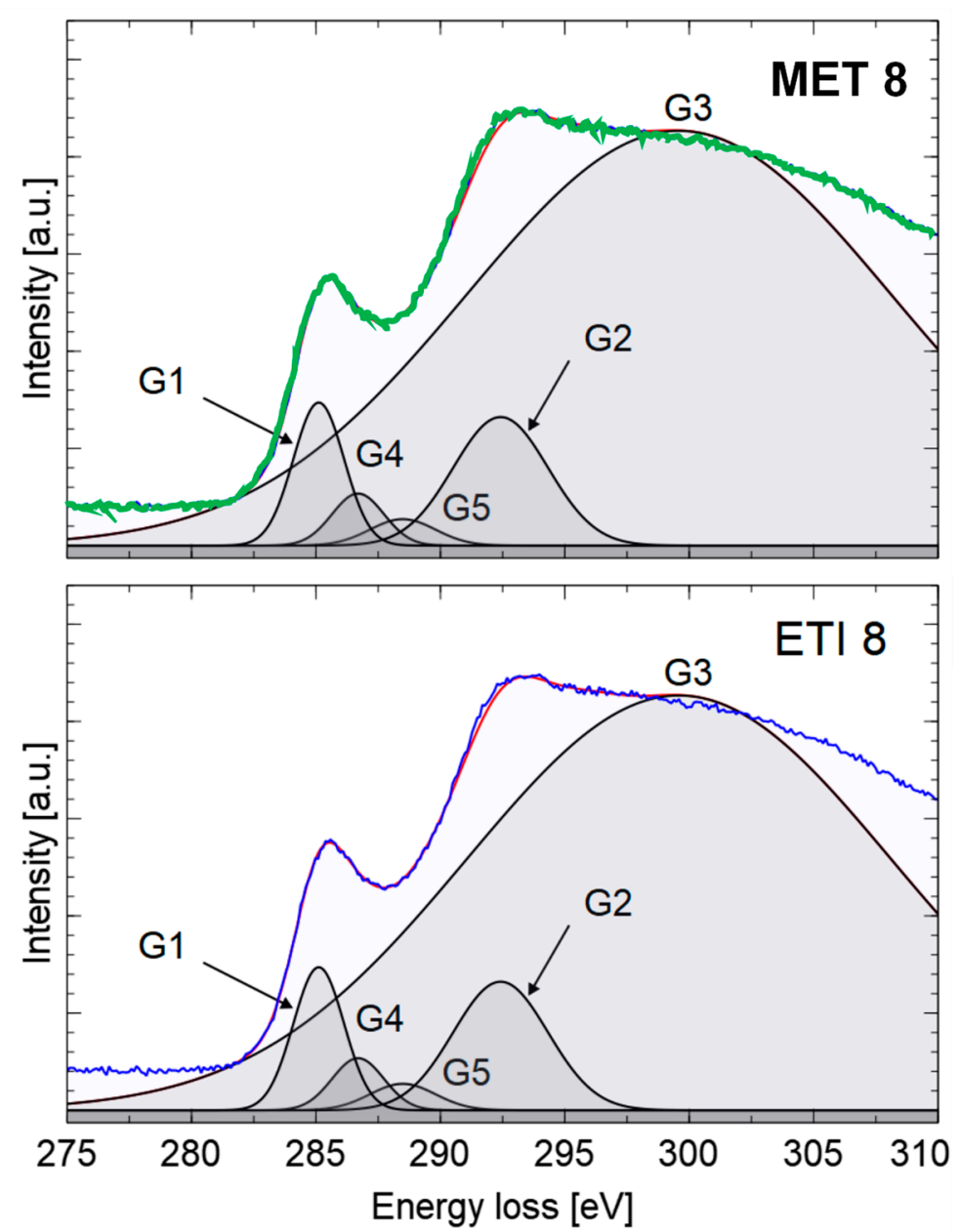

Figure 7. Deconvolution of the absorption curve $C_{K}$ of methane (up) and ethylene (down) soot.

According to the methodology presented in the paper [8], the planar $\mathrm{sp}^{2}$ content was calculated by comparing the ratio of the $\pi^{*}$ intensity (G1) with the total $\mathrm{C}_{\mathrm{K}}$-edge intensity, calculated over a $20-\mathrm{eV}$ window of onset $282.5 \mathrm{eV}$. It is proportional to the total number of carbon atoms present in the probed volume. The obtained ratio was normalized to the factor determined from spectra of a $100 \% \mathrm{sp}^{2}$-hybridized material [19-21], as shown in the Equation (1):

$$
\mathrm{sp}^{2} \text { content }=\left(\mathrm{I}_{\boldsymbol{\pi}^{*}} / \mathrm{I}_{\pi^{*}+\boldsymbol{\sigma}^{*}}\right) /\left(\mathrm{I}_{\boldsymbol{\pi}^{*}} / \mathrm{I}_{\boldsymbol{\pi}^{*}+\boldsymbol{\sigma}^{*}}\right)_{\text {std }}
$$

As reference material, graphite has been generally used in EELS studies since it presents $100 \% \mathrm{sp}^{2}$ content and a density of states of $1: 3 \pi^{*}: \sigma^{*}$ [4]. However, it was found that graphite suffers of orientation effects due to the fact that scattering cross-sectional areas depend on orientation. Therefore, in a previous work [5], a multifaceted polyhedral carbon, obtained by heat treatment of carbon black, was employed as a calibration standard, assuming it is $100 \% \mathrm{sp}^{2}$ (i.e., $1: 3 \pi^{*}: \sigma^{*}$ ). It presents a spherical geometry and, therefore, it is free of orientation effects. In the present paper, a similar material, a glassy carbon heated at $2500{ }^{\circ} \mathrm{C}$, which is a material containing near $100 \% \mathrm{sp}^{2}$ carbon hybridization [22], was used. For ethylene young soot, the percentage of total $\mathrm{sp}^{2}$ bonds is $85 \pm 4 \%$, which is very similar, in the error limit, to the percentage for methane young soot: $83 \pm 4 \%$. As soot is an $\mathrm{sp}^{2}$-rich aromatic disordered carbon [23], significant differences in terms of $\mathrm{sp}^{2}$ content for soot collected at the same stage of maturation were not expected. 
The fraction of $\mathrm{sp}^{2}$-bonded carbon atoms, which are bonded in a non-planar fashion, was determined as ratio according to the Equation (2):

$$
\mathrm{sp}^{2}{ }_{\mathrm{np}} / \mathrm{sp}^{2} \text { total }=\mathrm{I}_{\pi^{*} \mathrm{np}} / \mathrm{I}_{\pi^{*} \text { total }}
$$

where $\mathrm{I}_{\boldsymbol{\pi}^{*} \mathrm{np}}$ is the combined intensities under G4 and G5; $\mathrm{I}_{\boldsymbol{\pi}^{*} \text { total }}$ is the combined intensities under the G4, G5, and G1 peaks. For ethylene young soot, the percentage of non-planar fullerene-like $\mathrm{sp}^{2}$ bonds is $42 \pm 5 \%$, which is slightly lower with respect to that of methane young soot, which is: $46 \pm 5 \%$. The results are summarized in Table 1 .

Table 1. Percentage of total $\mathrm{sp}^{2}$ bonds and of non-planar fullerene like $\mathrm{sp}^{2}$ bonds as calculated for ethylene young (ETI8) and methane young (MET8) soot.

\begin{tabular}{ccc}
\hline Sample & Total sp ${ }^{2}$ Bonds, $\%$ & $\begin{array}{c}\text { Non-Planar Fullerene-Like } \\
\mathbf{s p}^{2} \text { Bonds, } \%\end{array}$ \\
\hline ETI8 & $85 \pm 4$ & $42 \pm 5$ \\
MET8 & $83 \pm 4$ & $46 \pm 5$ \\
\hline
\end{tabular}

This intensity ratio should reflect the degree of curvature of soot structure due to nonplanar, strained $\mathrm{sp}^{2}$ bonds. Therefore, EELS, in agreement with TEM and HRTEM, showed a somewhat disordered and heterogeneous structure for young soot, with a relatively low $\mathrm{sp}^{2}$ content and slight presence of fullerene-like structures, which are more evident in the case of methane soot, hinting at the effect of more saturated aliphatic fuels on soot characteristics at soot inception. The importance of being able to distinguish soot from different hydrocarbons is multiple. On the one hand, if the different fuel changes the structure of the soot, by studying the latter, one can trace the source of the emission of the soot [24]. On the other hand, the influence of the nature of the fuel on the nanostructure of the soot can help us to understand the soot formation mechanism.

\section{Conclusions}

In this paper, a method for the EELS spectrum analysis of carbonaceous materials recently developed for electron-irradiated graphite and glassy carbon composition analysis was tested for the first time on soot samples. The EELS results were compared to TEM and HRTEM observations.

The feasibility of quantitative EELS for evaluating the contribution of $\mathrm{sp}^{2}$ and $\mathrm{sp}^{3}$ bonds to soot nanostructure, distinguishing also between planar $\mathrm{sp}^{2}$ and non-planar fullerene-like $\mathrm{sp}^{2}$ bonds, was demonstrated.

EELS, in agreement with TEM and HRTEM, showed a somewhat disordered and heterogeneous structure for young soot, with a very low effect of more saturated aliphatic fuels as methane on the disorder and $\mathrm{sp}^{2}$ content of soot structure. As soot is an $\mathrm{sp}^{2}$-rich aromatic disordered carbon, significant differences in terms of $\mathrm{sp}^{2}$ content for soot collected at the same stage of maturation were not expected. Anyway, the present method is able to retrieve important information on the amount of planar $\mathrm{sp}^{2}$ and non-planar fullerene-like $\mathrm{sp}^{2}$ bonds, going beyond the identification of the $\mathrm{sp}^{2}$ hybridization degree. Thus, the effect of fuel chemical nature on soot, in terms of higher curvature in the structure with higher saturation degree, was put in evidence, even if it is slight.

Future work was planned for extending investigation on soot sampled at the exhaust and soot formed from different fuels (aromatics, oxygenated and so on), in order to check the reliability of the technique for correlating soot emission to its source. Pinpointing the exact sources of the pollution is important for policymakers working on addressing the pollution problem.

Author Contributions: Conceptualization, methodology, validation, investigation B.A., C.R., A.E.T., A.C. and M.P.; writing—original draft preparation B.A.; writing-review and editing, B.A., C.R., A.C. and M.P. All authors have read and agreed to the published version of the manuscript. 
Funding: This research received no external funding.

Institutional Review Board Statement: Not applicable.

Informed Consent Statement: Not applicable.

Data Availability Statement: Not applicable.

Conflicts of Interest: The authors declare no conflict of interest.

\section{References}

1. Apicella, B.; Pré, P.; Alfe, M.; Ciajolo, A.; Gargiulo, V.; Russo, C.; Tregrossi, A.; Deldique, D.; Rouzaud, J. Soot nanostructure evolution in premixed flames by High Resolution Electron Transmission Microscopy (HRTEM). Proc. Combust. Inst. 2015, 35, 1895-1902. [CrossRef]

2. Buseck, P.R.; Adachi, K.; Gelencsér, A.; Tompa, É.; Pósfai, M. Ns-soot: A material-based term for strongly light-absorbing carbonaceous particles. Aerosol Sci. Technol. 2014, 48, 777-788. [CrossRef]

3. Pósfai, M.; Buseck, P.R. Nature and Climate Effects of Individual Tropospheric Aerosol Particles. Annu. Rev. Earth Planet. Sci. 2010, 38, 17-43. [CrossRef]

4. Daniels, H.; Brydson, R.; Rand, B.; Brown, A. Investigating carbonization and graphitization using electron energy loss spectroscopy (EELS) in the transmission electron microscope (TEM). Philos. Mag. 2007, 87, 4073-4092. [CrossRef]

5. Apicella, B.; Ciajolo, A.; Tregrossi, A.; Abrahamson, J.; Wal, R.V.; Russo, C. HRTEM and EELS investigations of flame-formed soot nanostructure. Fuel 2018, 225, 218-224. [CrossRef]

6. Al-Qurashi, K.; Boehamn, A.L. Impact of exhaust gas recirculation (EGR) on the oxidative reactivity of diesel engine soot. Combust. Flame 2008, 155, 675-695. [CrossRef]

7. Baldelli, A.; Trivanovic, U.; Sipkens, T.A.; Rogak, S.N. On determining soot maturity: A review of the role of microscopy-and spectroscopy-based techniques. Chemosphere 2020 252, 126532. [CrossRef]

8. Mironov, B.E.; Freeman, H.M.; Brown, A.P.; Hage, F.S.; Scott, A.J.; Westwood, A.V.K.; Brydson, R.M.D. Electron irradiation of nuclear graphite studied by transmission electron microscopy and electron energy loss spectroscopy. Carbon 2015, 83, 106-117. [CrossRef]

9. Zhang, Z.-L.; Brydson, R.; Aslam, Z.; Reddy, S.; Brown, A.; Westwood, A.; Rand, B. Investigating the structure of nongraphitiing carbons using electron energy loss spectroscopy in the transmission electron microscope. Carbon 2011, 49, 5049-5063. [CrossRef]

10. Nyberg, M.; Luo, Y.; Triguero, L.; Pettersson, L.G.; Agren, H. Core-hole effects in X-ray-absorption spectra of fullerenes. Phys. Rev. $B$ 1999, 60, 7956-7960. [CrossRef]

11. Berger, S.D.; McKenzie, D.; Martin, P.J. EELS analysis of vacuum arc-deposited diamond-like films. Philos. Mag. Lett. 1988, 57, 285-290. [CrossRef]

12. Papworth, A.J.; Kiely, C.J.; Burden, A.P.; Silva, S.R.P.; Amaratunga, G.A.J. Electron-energy-loss spectroscopy characterization of the sp2 bonding fraction within carbon thin films. Phys. Rev. B 2000, 62, 12628-12631. [CrossRef]

13. Braun, A.; Huggins, F.; Shah, N.; Chen, Y.; Wirick, S.; Mun, S.; Jacobsen, C.; Huffman, G. Advantages of soft X-ray absorption over TEM-EELS for solid carbon studies-A comparative study on diesel soot with EELS and NEXAFS. Carbon 2005, 43, 117-124. [CrossRef]

14. Jurkiewicz, K.; Pawlyta, M.; Zygadło, D.; Chrobak, D.; Duber, S.; Wrzalik, R.; Ratuszna, A.; Burian, A. Evolution of glassy carbon under heat treatment: Correlation structure-mechanical properties. J. Mater. Sci. 2017, 53, 3509-3523. [CrossRef]

15. Apicella, B.; Barbella, R.; Ciajolo, A.; Tregrossi, A. Formation of low- and high-molecular-weight hydrocarbon species in sooting ethylene flames. Combust. Sci. Technol. 2002, 174, 309-324. [CrossRef]

16. Russo, C.; Apicella, B.; Tregrossi, A.; Oliano, M.M.; Ciajolo, A. Thermophoretic sampling of large PAH (C $\geq 22-24)$ formed in flames. Fuel 2020, 263, 116722. [CrossRef]

17. Wojdyr, M.J. Fityk: A general-purpose peak fitting program. J. Appl. Crystallogr. 2010, 43, 1126-1128. Available online: http:/ / www.unipress.waw.pl/fityk (accessed on 9 September 2021). [CrossRef]

18. Guerrero Peña, G.D.J.; Alrefaai, M.M.; Yang, S.Y.; Raj, A.; Brito, J.L.; Stephen, S.; Anjana, T.; Pillai, V.; Al Shoaibi, A.; Chung, S.H. Effects of methyl group on aromatic hydrocarbons on the nanostructures and oxidative reactivity of combustion-generated soot. Combust. Flame 2016, 172, 1-12. [CrossRef]

19. Williams, D.B.; Carter, C.B. Transmission Electron Microscopy, 2nd ed.; Springer: Berlin/Heidelberg, Germany, 2009.

20. Egerton, R.F. Electron Energy-Loss Spectroscopy in the Electron Microscope, 3rd ed.; Springer: Berlin/Heidelberg, Germany, 2011.

21. Brydson, R. Aberration-Corrected Analytical Electron Microscopy; John Wiley and Sons: Hoboken, NJ, USA, 2011.

22. Jurkiewicz, K.; Duber, S.; Fischer, H.E.; Burian, A. Modelling of glass-like carbon structure and its experimental verification by neutron and X-ray diffraction. J. Appl. Crystallogr. 2017, 50, 36-48. [CrossRef]

23. Russo, C.; Apicella, B.; Lighty, J.; Ciajolo, A.; Tregrossi, A. Optical properties of organic carbon and soot produced in an inverse diffusion flame. Carbon 2017, 124, 372-379. [CrossRef]

24. Wal, R.L.V.; Bryg, V.M.; Hays, M. Fingerprinting soot (towards source identification): Physical structure and chemical composition. J. Aerosol Sci. 2010, 41, 108-117. [CrossRef] 